\section{The Overall Proficiency in English Composition of Indonesian University Students of EFL}

\author{
Bambang Yudi Cahyono \\ Universitas Negeri Malang
}

\begin{abstract}
This study was aimed at examining the students' overall proficiency in English composition across university-year cohorts and across academic options. The participants were undergraduate students of Universitas Negeri Malang. They were asked to write persuasive essays on whether violence as exposed on TV programs should be restricted. The essays were evaluated using the ESL Composition Profile. The results showed that that there was a significant difference between the first- and fourth-year students' overall proficiency in English composition. In addition, there was no significant difference between the overall proficiency in English composition of the students taking the thesis option and those taking non-thesis option. The instructional program and writing curriculum appeared to play an important role in developing the students' overall proficiency in English composition. However, the thesis prerequisite courses provided to prepare the students to write a thesis proposal did not seem to affect their overall proficiency in English composition.
\end{abstract}

Key words: overall proficiency in English composition, thesis prerequisite courses, ESL composition profile, writing instruction, writing courses.

In the English Department of Universitas Negeri Malang, writing instruction is given through a series of writing courses. In the first semester, undergraduate students take a prerequisite course called the Intensive Course Program. This program is aimed at developing the students' command of English to prepare them to take other courses offered in the department. In this program, language skills (listening, speaking, reading, and writing) and language elements (vocabulary, grammar, and pronunciation) are taught in an integrated manner. Writing exercises are mainly given at a sentence level. Writing above the sentence level focuses on personalized express-ions of experience, the purpose of which is to provide more opportunities for the stu-dents to write.

Further writing courses which are given in the next four semesters have different purposes. Writing I emphasizes paragraph writing based on model paragraphs of various genres. Writing II teaches the students to develop ideas into an essay with an emphasis on the organization of the essay. Writing III provides the students with opportunities to write more essays requiring various techniques of development, such as the cause and effect essay or the comparison and contrast essay. Writing IV focuses on the development of an argumentative type of writing, i.e. one with problem-solution patterns. Included in this advanced writing course is the instruction of the persuasive type of writing.

The students in the English Department may choose one of two academic options in their study, i.e. the thesis or non-thesis options. The thesis option requires the students to take three additional courses, i.e. Introduction to Thesis Writing, Thesis Proposal Seminar, and Research Statistics. These courses provide the students with more writing practice to prepare them to produce a thesis proposal. The non-thesis option does not require the students to take the additional courses.

A study conducted previously indicated that undergraduate students of the English Department did not necessarily write essays of better quality as they took more courses. Latief (1990) carried out a study on the effectiveness of the writing curriculum at the same English Department. Latief's research was aimed at assessing the coherence, syntactic, grammatical, and mechanical quality of the students' descriptive and argumentative writing across different years of study, from the second up to the fourth year. Latief also aftempted to demonstrate how the primary-trait scoring system (see also Schultz and Laine, 1986) could be used to assess the students' essays.

Latief found that the university year cohorts did not necessarily indicate differences in the proficiency of the students in writing descriptive essays coherently. Comparison of the coherence quality of the argumenta- 
tive essays written by the fourth-year and the third-year students indicated that the essays written by the fourth-year students were more coherent than those written by the third-year students. In terms of sentence construction, the essays written by the three groups of students did not show differences in the complexity of sentences. Most of the sentences in the essays were simple or complex sentences; very few of them were compound or compound-complex sentences. In terms of sentence length, the students did not write longer descriptive essays as they had longer study period and took more courses. With regard to grammatical and mechanical qualities, the students did not make fewer errors as they took more courses. Latief also found that the primary-trait scoring was effective for assessing the rhetorical quality of the students' writing and it could be implemented without any difficulty.

Examining the results of research reported by Latief, it is intriguing to investigate the students' overall proficiency in English composition. In order to gain data reflecting the outcome of writing instruction, this study involved the first- and fourth-year students. The learning outcome was expected to differ according to the length of exposure to English instruction and, particularly, to writing instruction. In addition, an attempt needed to be made to examine the effect of courses related to writing on the students' overall proficiency in English composition. The courses related to writing are the thesis prerequisite courses.

The purpose of this study was to evaluate the overall proficiency in English composition of the students across university-year cohorts and academic options. The research questions were formulated as follows:

- Does the overall proficiency in English composition of the first-year students differ from that of the fourth-year students?

- Does the overall proficiency in English composition of the fourth-year students taking the thesis option differ from that of the fourth-year students taking the non-thesis option?

\section{METHOD}

The participants in this study were undergraduate students of Universitas Negeri Malang. The first- and fourth-year students were asked to write persuasive essays on whether violence on TV programs should be restricted. To find out which of the fourth-year students were taking the thesis option, a questionnaire was distributed.

The data collection took place in September and October 1999. Prior to the actual data collection, a pilot study was conducted in two out of five classes of first-year students. The purpose of the pilot study was to examine whether the prompts of the writing task had been understood. The essays from the pilot study were used in the practice session of scoring. Two other classes of the first-year students and three classes of the fourth-year students were involved in the actual data collection. Forty essays from each group were selected randomly by using a table of random numbers. The data from the questionnaire indicated that out of 40 fourth-year students, 19 students were taking or had taken the three thesis prerequisite courses and 15 students were taking the non-thesis option. These two groups of students were compared to know whether the thesis prerequisite courses affected the students' overall proficiency in English composition. The other students had not decided whether they would take the thesis option or they had taken one thesis prerequisite course. The essays of these students were not used in the analysis.

The students' overall proficiency in English composition was evaluated using the ESL Composition Profile (Jacobs, et al., 1981). This profile was used because it was designed to help teachers of English for speakers of other languages evaluate learners' compositions in a practical way. As emphasized by Hartfiel, et al. (1985), the profile is useful as a guideline for leamers to learn ESL composition because it clearly shows the components of writing and the criteria of evaluation. Most importantly, this profile had been applied in the English Department where the study was carried out.

The ESL Composition Profile divides writing into five components with various percentages, i.e. content (30\%), organization $(20 \%)$, vocabulary $(20 \%)$, language use (25\%) and mechanics $(5 \%)$. Each component has a set of criteria ranging from "excellent to very good" to "very poor" with a 
specified range of scores. The profile assumes 100 as the highest possible score for overall proficiency in English composition.

The scoring of the essays was done by two raters. The raters were faculty members of the English Department of the same university. These raters had more than 10 years of experience in teaching English and in evaluating English compositions. To make sure that the profile was applied correctly in assigning scores for each essay, the raters were trained in a workshop session. In this session, the procedures for applying this measure were first explained. The raters were then asked to score five of the essays gathered from the pilot study and the scores were compared. Different scores were discussed in an attempt to arrive at an agreement in the rating. At the end of discussion, an agreement was finally reached for the total scores and for the components of the system as well.

The interrater reliability was computed to see the effectiveness of the ESL Composition Profile used for scoring the students' essays. In addition, an attempt was also made to examine differences in scoring between the first and the second raters using the Wilcoxon matched-pairs signed-ranks test. This test was used because it takes into account the magnitude and the direction of the difference for each pair of scores (Huck, et al., 1974:204). To analyze the differences in the students' overall proficiency in English composition across university-year cohorts and across academic options, the $t$-test was used. The probability level to judge the statistical significance was .05.

The total scores of overall proficiency in English composition were the sum of scores of content, organization, vocabulary, language use, and mechanics components. The interrater reliability for the total scores of overall proficiency in English composition was .90. For the total scores of the essays, the first rater assigned 38 essays $(47.5 \%)$ greater scores than the second rater did, whereas the second rater also assigned 38 essays $(47.5 \%)$ greater scores than the first rater did. Four essays $(5 \%)$ received the same scores from the two raters. The difference in scoring between the two raters was not statistically significant (Wilcoxon matched-pairs signed-ranks test, $z=-0.67, p>.05, N=80$ )

\section{RESULTS}

The combined scores of the two raters were used as a reference for the overall proficiency in English composition. The scores of the first- and fourth-year students on overall proficiency in English composition are presented in Table 1. The table shows that the lowest score of the first-year students is 40 and the highest score is 91.5 . The lowest score of the fourthyear students is 53.5 and the highest score is 99 .

Table 1 Scores of the First-and Fourth-year Students on Overall Proficiency in English Composition (Mean Scores of 2 Raters)

\begin{tabular}{|c|cc|c|cc|c|cc|c|cc|}
\hline 01 & 57 & 65 & 11 & 69 & 94 & 21 & 49 & 91.5 & 31 & 68 & 77.5 \\
\hline 02 & 63.5 & 74.5 & 12 & 85 & 78 & 22 & 45.5 & 99 & 32 & 54.5 & 94.5 \\
\hline 03 & 76 & 91 & 13 & 49 & 84.5 & 23 & 42.5 & 83 & 33 & 69.5 & 70 \\
\hline 04 & 68 & 78 & 14 & 75 & 86.5 & 24 & 77.5 & 85 & 34 & 73 & 72 \\
\hline 05 & 59.5 & 77.5 & 15 & 74.5 & 83.5 & 25 & 71 & 90 & 35 & 48 & 79.5 \\
\hline 06 & 58 & 87 & 16 & 72 & 85.5 & 26 & 69.5 & 85 & 36 & 53 & 83.5 \\
\hline 07 & 76.5 & 90.5 & 17 & 69 & 89.5 & 27 & 64 & 84.5 & 37 & 40 & 96.5 \\
\hline 08 & 69 & 82 & 18 & 60.5 & 95.5 & 28 & 71 & 53.5 & 38 & 91.5 & 76 \\
\hline 09 & 75 & 97 & 19 & 83 & 96.5 & 29 & 45 & 91.5 & 39 & 69.5 & 87.5 \\
\hline 10 & 65 & 92 & 20 & 70 & 83.5 & 30 & 64 & 85.5 & 40 & 72.5 & 87.5 \\
\hline
\end{tabular}

The mean of overall proficiency in English composition of the firstyear students is 65.33 , while that of the fourth-year students is 84.36 . Table 2 shows that there is a significant difference between overall proficiency in English composition of the first- and fourth-year students. 
Table 2 A Comparison of Overall Proficiency in English Composition of the First- and Fourth-year Students (Mean Scores of 2 Raters)

\begin{tabular}{lcccc}
\hline Group & N & Mean & SD & $t$ \\
\hline First-year students & 40 & 65.33 & 12.04 & \\
Fourth-year students & 40 & 84.36 & 9.30 & $-7.92^{*}$ \\
\hline
\end{tabular}

$*_{\mathrm{p}}<.05$

Further examination was focused on the means of the components of the profile. The means of content, organization, vocabulary, language use, and mechanics of the first-year students' essays were 19.8, 13.8, 13.2, 15, and 3.6 respectively. The means of content, organization, vocabulary, language use, and mechanics of the fourth-year students' essays were 25.2, $17.7,17.1,20$, and 4.4, respectively. Figure 1 exhibits the means of the components of proficiency of the two groups. As shown in the figure, the fourth-year students were more successful than the first-year students in all of the components of proficiency in English composition.

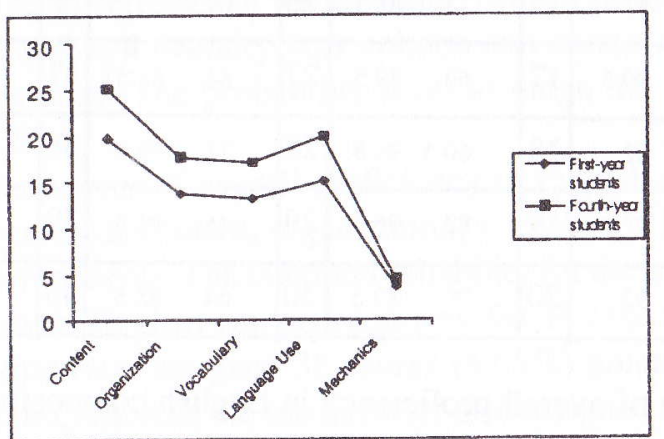

Figure 1 Means of Components of Proficiency in English Composition of the First- and Fourth-year Students

Based on the criteria in the ESL Proficiency profile used to evaluate the essays, the two groups' means of proficiency components can be de- scribed further. In terms of content, the first-year students' essays contained limited knowledge of subject, limited idea substance, and inadequate topic development. Conversely, the fourth-year students' essays contained some knowledge of subject, adequate range of ideas, and some development of thesis. With regard to organization, the first-year students' essays were loosely organized and not entirely sequenced, whereas the fourth-year students' essays were fluently expressed, well organized, and logically sequenced. In terms of vocabulary, the first-year students' essays contained a limited range of vocabulary and frequent errors of word choice and usage. Unlike the first-year students' essays, the fourth-year students' contained an adequate range of vocabulary and occasional errors of word choice and usage. Concerning language use, the first-year students' essays contained major problems in simple or complex construction and frequent errors of tense and parts of speech. In contrast, the fourth-year students' essays contained minor problems in sentence construction and several errors of tense and parts of speech. In terms of mechanics, the first-year students' essays were likely to contain occasional errors of spelling, punctuation, capitalization, and paragraphing. Conversely, the fourth-year students' essays were likely to demonstrate mastery of conventions and contain fewer errors of spelling, punctuation, capitalization, and paragraphing.

The status of the students in taking the thesis and non-thesis options did not appear to affect overall proficiency in English composition of the fourth-year students. Table 3 shows that there is no significant difference in the overall proficiency in English composition of the fourth-year students taking the thesis and non-thesis options.

Table 3 A Comparison of Overall Proficiency in English Composition of the Fourthyear Students Taking the Thesis and Non-thesis Options (Mean Scores of 2 Raters)

\begin{tabular}{llllll}
\hline Group & N & Mean & SD & \multirow{t}{*}{} \\
\hline The students taking the thesis option & 19 & 85.68 & 8.42 & \\
The students taking the non-thesis option & 40 & 84.36 & 9.30 & $1.41^{*}$ \\
\hline
\end{tabular}


Because there was no significant difference in the overall proficiency in English composition of the students taking the thesis and non-thesis options, it can be argued that there is no basis for further examination of the components of overall proficiency in English composition.

\section{DISCUSSION}

The difference of overall proficiency in English composition was shown between the first- and fourth-year students. The examination of the components of proficiency indicated that the fourth-year students were more successful in all of the components of proficiency in English composition, including content, organization, vocabulary, language use, and mechanics. The difference was likely to be attributed to the role of the instructional program in the department. The first-year students were in their beginning stage of study, while the fourth-year students had taken all writing courses and some of them were taking or had taken the thesis prerequisite courses.

Although the instructional program in the department was likely to influence the students' overall proficiency in English composition, the three thesis prerequisite courses did not appear to cause any difference in the overall proficiency in English composition of the fourth-year students. This was evident from the lack of significant difference in the overall proficiency in English composition of students who took the thesis and nonthesis options. A possible reason underlying this might be that the total credits of the prerequisite courses ( 6 credits) are too small to cause any difference in the overall proficiency in English composition of the students taking the thesis and non-thesis options. Another possible reason might be that both the students taking the thesis and non-thesis options had reached the threshold level of proficiency in English composition as established in the curriculum of writing courses. Another possible reason might be that the thesis prerequisite courses are related to a particular genre of writing, i.e. thesis proposal writing, which might not be directly related to the students' overall proficiency in English composition. However, the findings and the hypotheses should be treated with care because of the limited number of participants taking the thesis and non-thesis options involved in this study.

\section{CONCLUSIONS AND SUGGESTIONS}

In light of the results of the study and the discussion of the results, two conclusions can be drawn. First, the instructional program in general and writing courses in particular appeared to play a role in developing the students' overall proficiency in English composition. Second, although additional thesis prerequisite courses were designed to prepare the students to write a thesis proposal, these courses did not seem to affect the students' overall proficiency in English composition.

The comparison of the overall proficiency in English composition in this study involved students from two extreme levels: the first- and fourthyear. Future research might involve the second- and third-year students as well to provide a more detailed description of the students' overall proficiency in writing composition across all university-year cohorts.

\section{REFERENCES}

Harfiel, V.F., Jacobs, H.L., Zinkgraft, S.A., Wormuth, D.R., and Hughey, J.B. 1985. Learning ESL Composition. Rowley, Massachusetts: Newbury House.

Huck, S.W., Cormier, W.H., and Bounds, W.G. 1974. Reading Statistics and Research. New York: Harper and Row.

Jacobs, H.L., Zinkgraf, S.A., Wormuth, D.R., Hartfiel, V.F., and Hughey, J.B. 1981. Testing ESL Composition: A Practical Apprach. Rowley, Massachusetts: Newbury House.

Latief, M.A. 1990. Assessment of English Writing Skills for Students of English as a Foreign Language at the Institute of Teacher Training and Education IKIP MALANG Indonesia. Dissertation. Iowa: The University of Iowa.

Schultz, L.M., and Laine, C.M. 1986. A Primary Trait Scoring Grid with Assessment and International Uses. Joumal of Teaching Writing, 5:77-89. 